(6) OPEN ACCESS

\title{
Modern diagnosis of GERD: the Lyon Consensus
}

\author{
C Prakash Gyawali, ${ }^{1}$ Peter J Kahrilas, ${ }^{2}$ Edoardo Savarino, ${ }^{3}$ Frank Zerbib ${ }^{4}$ \\ Francois Mion, ${ }^{5,6,7}$ André J P M Smout, ${ }^{8}$ Michael Vaezi, ${ }^{9}$ Daniel Sifrim, ${ }^{10}$ \\ Mark R Fox, ${ }^{11,12}$ Marcelo F Vela, ${ }^{13}$ Radu Tutuian, ${ }^{14}$ Jan Tack, ${ }^{15}$ Albert J Bredenoord, ${ }^{8}$ \\ John Pandolfino, ${ }^{2}$ Sabine Roman ${ }^{5,6,7}$
}

For numbered affiliations see end of article.

\section{Correspondence to}

Professor C Prakash Gyawali, Division of Gastroenterology, Washington University School of Medicine, St. Louis, MO 63110, USA; cprakash@wustl.edu

Received 26 December 2017 Revised 11 January 2018 Accepted 14 January 2018 Published Online First 3 February 2018
Check for updates

To cite: Gyawali $\mathrm{CP}_{1}$ Kahrilas PJ, Savarino E, et al. Gut 2018:67:1351-1362.

\section{ABSTRACT}

Clinical history, questionnaire data and response to antisecretory therapy are insufficient to make a conclusive diagnosis of GERD in isolation, but are of value in determining need for further investigation. Conclusive evidence for reflux on oesophageal testing include advanced grade erosive oesophagitis (LA grades ( and D), long-segment Barrett's mucosa or peptic strictures on endoscopy or distal oesophageal acid exposure time (AET) $>6 \%$ on ambulatory $\mathrm{pH}$ or $\mathrm{pH}$ impedance monitoring. A normal endoscopy does not exclude GERD, but provides supportive evidence refuting GERD in conjunction with distal AET $<4 \%$ and $<40$ reflux episodes on $\mathrm{pH}$-impedance monitoring off proton pump inhibitors. Reflux-symptom association on ambulatory reflux monitoring provides supportive evidence for reflux triggered symptoms, and may predict a better treatment outcome when present. When endoscopy and $\mathrm{pH}$ or $\mathrm{pH}$-impedance monitoring are inconclusive, adjunctive evidence from biopsy findings (histopathology scores, dilated intercellular spaces), motor evaluation (hypotensive lower oesophageal sphincter, hiatus hernia and oesophageal body hypomotility on high-resolution manometry) and novel impedance metrics (baseline impedance, postreflux swallow-induced peristaltic wave index) can add confidence for a GERD diagnosis; however, diagnosis cannot be based on these findings alone. An assessment of anatomy, motor function, reflux burden and symptomatic phenotype will therefore help direct management. Future GERD management strategies should focus on defining individual patient phenotypes based on the level of refluxate exposure, mechanism of reflux, efficacy of clearance, underlying anatomy of the oesophagogastric junction and psychometrics defining symptomatic presentations.

\section{INTRODUCTION}

GERD has an estimated worldwide prevalence of $8 \%-33 \%$, involves all age groups and both genders ${ }^{1}$ and carries a price tag estimated at >US\$9US $\$ 10$ billion/year in the USA alone, largely related to proton pump inhibitors (PPI) use and diagnostic testing. ${ }^{2}$ The current paradigm of GERD diagnosis hinges on the identification of oesophageal mucosal lesions or troublesome symptoms caused by gastro-oesophageal reflux. ${ }^{3}$ A putative GERD diagnosis is bolstered by a favourable response to PPI therapy. ${ }^{4}$ The primary determinant of mucosal injury is excessive oesophageal acid exposure attributable to anatomical or physiological defects of the oesophagogastric junction (EGJ) and oesophageal peristalsis. ${ }^{5}$
GERD symptoms, however, have multiple potential determinants including the number of reflux episodes, the proximal extent to which the refluxate migrates, the acidity of the refluxate, oesophageal hypersensitivity and cognitive hypervigilance. Consequently, depending on the clinical context, the defining features of GERD can be pathology, physiology or symptomatology. In this paradigm, oesophageal testing is often undertaken to define optimal management, be that PPI therapy, antireflux surgery (ARS) or cognitive behavioural therapy.

The aim of the GERD consensus process was to determine modern indications for oesophageal testing in GERD, and as an extension to that aim, to define criteria for a clinical diagnosis of GERD. The consensus process started in 2014, when the primary aims were formulated, followed by a literature search and grading of evidence. There was extensive discourse within a multinational group of GERD experts over 2 years, following which consensus statements were developed and published. $^{6-8}$ These consensus statements were adapted for the practising gastroenterologist by a cohort of international experts at the Lyon GERD consensus meeting in November 2017, the conclusions from which are presented in this manuscript.

\section{DIAGNOSIS OF GERD}

GERD is empirically diagnosed and treated in clinical practice based on the clinician's symptom assessment. Indications for testing include treatment failure, diagnostic uncertainty and treating (or preventing) complications of GERD. However, diagnostic testing may or may not support the initial diagnosis, as the criteria defining GERD are specific to each testing modality. Consequently, understanding the performance characteristics of each diagnostic modality and recognising evidence that supports or refutes the clinical impression of GERD is crucial. The Lyon Consensus evaluated GERD diagnostic tests from that perspective, and test results were categorised as being adequate to establish or refute a GERD diagnosis or inconclusive in the absence of additional supportive evidence.

The primary focus of oesophageal testing has hitherto been restricted to detection of excessive acid reflux as indicative of pathological GERD, supported by reflux-symptom association analysis. The threshold value discriminating abnormal from normal oesophageal acid exposure with 24 hour pH-metry was initially selected based on evidence that higher acid exposure is associated with the presence of reflux oesophagitis. ${ }^{9}$ However, the focus of 
current GERD management is on healing mucosal disease and on managing symptoms. The association of oesophageal acid exposure with patient symptoms is weak, ${ }^{10} 11$ making sole reliance of this metric problematic. Expansion of testing to include oesophageal mucosal impedance, manometry, histopathology and psychometrics may help in this regard, potentially identifying distinct GERD phenotypes with unique management implications. Each test adds a piece to the overall puzzle of symptom generation, disease pathophysiology and precision management.

\section{Clinical history and questionnaires}

Typical GERD symptoms (heartburn and acid regurgitation) are more likely than atypical symptoms to respond to treatment, emphasising the value of an accurate clinical history. ${ }^{5}$ However, when compared with objective evidence of GERD defined by $\mathrm{pH}$-metry or endoscopy, even an expert history by a gastroenterologist has only $70 \%$ sensitivity and $67 \%$ specificity, ${ }^{12}$ reiterating the distinction between a physiology-based and a symptom-based GERD diagnosis. Likewise, questionnaires such as the reflux disease questionnaire (RDQ) and gastroesophageal reflux disease questionnaire (GERDQ) have similar limitations when compared with physiological testing. ${ }^{12-14}$ However, in clinical practice, diagnosing and treating GERD based on typical symptoms is pragmatic and endorsed by societal guidelines, ${ }^{4}$ even though these symptoms are neither sensitive nor specific for objectively defined GERD. ${ }^{12}$

\section{Proton pump inhibitor trial}

Although pragmatic, symptomatic response to PPI therapy does not equate to a GERD diagnosis, exhibiting an imperfect correspondence with objectively defined disease. On average, 69\% of patients with oesophagitis, $49 \%$ of patients with non-erosive reflux disease (NERD) and 35\% of patients with normal endoscopy and $\mathrm{pH}$-metry gain symptom relief from a PPI trial. ${ }^{15}$ Hence, when evaluated as a diagnostic test for GERD among patients with heartburn, an empiric PPI trial has a sensitivity of $71 \%$ and specificity of only $44 \%$ compared with the combination of endoscopy and $\mathrm{pH}$-metry. ${ }^{12}{ }^{16}$ With atypical symptoms (chest pain, chronic cough, laryngitis, etc), PPI response rates are much lower than with heartburn, thereby diminishing the utility of that approach to diagnosis. ${ }^{17} \mathrm{~A}$ major limitation of the 'PPI test' is the strong modulation of symptoms by oesophageal hypersensitivity ${ }^{18}{ }^{19}$; there is also variation in PPI dosing and duration of the test. ${ }^{20}$ Nonetheless, despite low specificity and high placebo response, ${ }^{21}$ the empiric PPI treatment approach is less costly than diagnostic testing 22 and is endorsed by societal guidelines ${ }^{4}$ undoubtedly leading to the overdiagnosis of GERD and overuse of PPIs.

\section{Endoscopy and biopsy}

When putative GERD symptoms do not respond to empiric PPI therapy, upper endoscopy (EGD) is advised both to evaluate for GERD complications and to detect potential alternative diagnoses that might redirect therapy. High-grade oesophagitis (LA grades $\mathrm{C}$ or D), Barrett's oesophagus or peptic stricturing are considered confirmatory evidence for GERD. ${ }^{6}$ However, erosive oesophagitis is found in only $30 \%$ of treatment-naïve patients with heartburn and in $<10 \%$ when already taking a PPI. ${ }^{23} 24$ Furthermore, most of that is low-grade, and lower grades of oesophagitis, particularly LA grade A, are non-specific, found in $5 \%-7.5 \%$ of asymptomatic controls. ${ }^{25-27}$ When accurately defined, LA grade B oesophagitis provides adequate evidence for initiation of medical management of GERD, but problems with interobserver variability led an expert panel to conclude that additional $\mathrm{pH}$-metry evidence is requisite prior to pursuing ARS. $^{28}$ Barrett's oesophagus is observed in 5\%-15\% of patients with chronic GERD, ${ }^{29-31}$ but histological confirmation is documented in only $50 \%$ of these. In summary, EGD findings can be clinically important and specific for GERD, but EGD has a low sensitivity in GERD diagnosis.

The Rome IV consensus recommended oesophageal biopsies during EGD to rule out eosinophilic oesophagitis. ${ }^{32}$ Biopsies may also have value in differentiating NERD (with positive pH-metry) from reflux hypersensitivity, functional heartburn and controls when scored using a structured histopathological protocol evaluating papillary elongation, basal cell hyperplasia, dilated intercellular spaces, intraepithelial inflammatory cells, necrosis and erosions ${ }^{33} 34$; changes that resolve following adequate GERD therapy. ${ }^{35}$ However, histopathological findings can overlap between the groups studied, and are not conclusive of GERD. Identification of dilated intercellular spaces on electron microscopy suggests mucosal injury from reflux, ${ }^{36}$ but clinical application is limited. The widespread adoption of histopathological examination for GERD injury is hindered by the cumbersome protocol and need for a dedicated oesophageal pathologist. 333839

\section{Ambulatory reflux monitoring}

Ambulatory reflux monitoring can provide confirmatory evidence of GERD, in patients with normal endoscopy, atypical symptoms and/or when contemplating ARS. ${ }^{6}$ Reflux monitoring demonstrates the consequence of GERD pathophysiology, evident as either excessive oesophageal acid exposure time (AET) or reflux episodes, rather than the mechanism by which that occurs. Reflux-symptom association uses simple ratios and statistical tests to determine whether reflux episodes co-occur with symptoms, and adds value to ambulatory reflux monitoring. Hence, reflux monitoring can confirm or exclude pathological GERD, although not always conclusively.

The primary outcome of a 24-hour pH-metry study is the AET. Extending recording time to 48 or 96 hours with the wireless $\mathrm{pH}$ monitoring system increases the diagnostic yield ${ }^{40-42}$ and test reproducibility, ${ }^{43}$ and is particularly useful when a transnasal catheter was not tolerated or yielded a negative result despite high suspicion of GERD. ${ }^{40} 44$ However, wireless $\mathrm{pH}$ monitoring is expensive, limiting its availability. Another variation on reflux monitoring is $\mathrm{pH}$-impedance monitoring, which characterises reflux events with both a $\mathrm{pH}$ electrode and a series of impedance electrodes. Since $\mathrm{pH}$-impedance detects all reflux (liquid, gas or mixed) regardless of acidity, and defines the direction of flow, it is considered the gold standard. ${ }^{645}$ However, the added yield is limited, ${ }^{4647}$ the test is not widely available and the interpretation is laborious.

Reflux monitoring can be done 'on' or 'off' PPI therapy in patients with persistent and/or atypical symptoms despite PPI therapy. The Lyon Consensus proposes that testing always be performed off therapy to demonstrate baseline AET in 'unproven GERD', meaning no (or low-grade) oesophagitis at endoscopy, and no prior positive $\mathrm{pH}$ testing. ${ }^{8}$ Testing off therapy is also recommended when done to evaluate for ARS. ${ }^{6}{ }^{32}$ In contrast, the Lyon Consensus proposes that patients with 'proven GERD' (prior LA grade C or D oesophagitis, long segment Barrett's oesophagus or prior abnormal $\mathrm{pH}$-metry) be evaluated on double-dose PPI therapy to establish correlation between refractory symptoms and reflux episodes and/or to exclude inadequate acid suppression or poor compliance as the mechanism of persisting symptoms. This assessment requires $\mathrm{pH}$-impedance (vs $\mathrm{pH}$ ) monitoring since most reflux episodes on PPI therapy are weakly acidic ( $\mathrm{pH} 4-7){ }^{4849}$ 
Assessment of proximal oesophageal or pharyngeal reflux has also been proposed, but methodology and interpretation have not been standardised, and outcome studies are currently lacking. ${ }^{50-53}$ An additional problem with the pharyngeal $\mathrm{pH}$ probe designed to evaluate both aerosolised and liquid acid reflux $^{54}$ is that it detects pharyngeal $\mathrm{pH}$ drops in the absence of concomitant oesophageal $\mathrm{pH}$-impedance events, ${ }^{55}{ }^{56}$ even in patients post-gastrectomy, raising questions about its accuracy. ${ }^{57}$

\section{Interpretation of $\mathrm{pH}$ and $\mathrm{pH}$-impedance monitoring}

Among the $\mathrm{pH}$ monitoring metrics, AET is the most reproducible,${ }^{58}$ is reliably extracted from automated analysis and is predictive of response from medical and surgical reflux therapy. ${ }^{59} 60$ However, the significance of an abnormal AET is proportionate to the degree of abnormality, and the Lyon Consensus proposes that AET $<4 \%$ be considered definitively normal (physiological) and $>6 \%$ be considered definitively abnormal ${ }^{6}$ with intermediate values between these limits being inconclusive. Another outcome metric of $\mathrm{pH}$-impedance monitoring is the number of reflux episodes (acidic, weakly acidic or weakly alkaline) with the caveat that this is overestimated by the automated analysis and requires manual review of the tracing. ${ }^{61}$ The Lyon GERD Consensus proposes that $>80$ reflux episodes per 24 hours are definitively abnormal, while a number $<40$ is physiological ${ }^{6}$ and intermediate values inconclusive. The clinical relevance of an abnormal number of reflux episodes remains incompletely defined, although recent preliminary data demonstrate improvement of regurgitation verified by increased reflux episodes following magnetic sphincter augmentation. ${ }^{62}$ Consequently, this is considered an adjunctive measure to be used when AET is inconclusive (ie, between $4 \%$ and $6 \%$ ). pH-Impedance monitoring assists diagnosis of belching disorders and rumination, which can mimic reflux disease. Additional impedance parameters such as bolus exposure, baseline impedance and postreflux swallow-induced peristaltic wave (PSPW) also have potential as reflux metrics, but outcome data are currently limited.

\section{Reflux-symptom association}

Both $\mathrm{pH}$ monitoring and combined $\mathrm{pH}$-impedance monitoring provide analysis of the temporal association between symptoms with a crisp onset (eg, heartburn, regurgitation, chest pain, cough or belching) and reflux episodes. ${ }^{63}$ The time window applied for reflux-symptom association analysis is $2 \mathrm{~min}^{.6465}$ The Symptom Index (SI) is the percentage of symptom events preceded by reflux episodes, ${ }^{66}$ and the optimal SI threshold for heartburn is $50 \% .{ }^{67}$ The disadvantage of the SI is that the number of reflux episodes is not considered leaving open the possibility of chance association. The Symptom Association Probability (SAP) and the Ghillebert Probability Estimate (GPE), also known as Binomial Symptom Index (BSI), use more complex statistical calculations to express the probability that symptom events and reflux episodes are associated $^{68}{ }^{69}$ and are considered positive if the probability (P value) of the observed association occurring by chance is $<5 \%$. Both SAP and GPE/BSI take all relevant components, that is, total numbers of symptom events, reflux episodes and reflux-related symptom events, into account. In summary, SI is a measure of 'effect size', whereas SAP is a measure of probability. As such the two metrics are complementary, measure different things and cannot be compared with each other. The combination of a positive SI and positive SAP provides the best evidence of a clinically relevant association between reflux episodes and symptoms. ${ }^{67071}$ Both the SI and SAP are predictive of the effect of medical and surgical antireflux therapy, independent of AET. ${ }^{72-75}$
The reliability of reflux-symptom association analysis is critically dependent on proper execution of the reflux monitoring procedure and meticulous analysis protocols including careful selection of symptoms of interest. Patients must be instructed to use the symptom event button on the portable data logger accurately and to fill in the symptom diary accurately. The outcome of symptom association analysis is more reliable when at least three symptom events occur during the test. ${ }^{6}$ When cough is the symptom of interest, an automated acoustic or manometric cough monitor is necessary to accurately capture cough events. ${ }^{777}$ Prolonged wireless $\mathrm{pH}$ monitoring increases the yield of symptom association analysis, ${ }^{4041}$ as does combined $\mathrm{pH}$-impedance monitoring with the detection of weakly acidic reflux episodes. ${ }^{78}$ This requires manual analysis, as automated analysis significantly overdetects weakly acidic reflux episodes and inaccurately reports association with non-acid reflux events in nearly $20 \%$ of cases. ${ }^{61}$ However, 'rapid' visual analysis limited to the 2 min window preceding each symptom event yields SI and SAP values concordant with a full visual analysis, with excellent intraobserver and interobserver agreement. ${ }^{79}$ Although $\mathrm{pH}$-impedance monitoring provides analysis of symptom-reflux association on PPI therapy, testing off PPI therapy increases the number of symptoms reported, which increases the chance of a positive symptom-reflux association. ${ }^{80}$

Reflux-symptom association analysis has a high degree of reproducibility, the SI being somewhat less reproducible than the SAP. ${ }^{81}$ Monte Carlo simulations have identified limitations of reflux-symptom association analysis, especially when acid exposure is low and symptom events are few. ${ }^{82} 83$ If new methods for reflux-symptom association are developed in the future, rigorous outcome testing will be needed to define superiority to the existing metrics.

\section{Novel metrics}

Two novel impedance-detected parameters, the PSPW index and baseline impedance have been investigated within GERD phenotypes. ${ }^{84} 85$ These metrics may augment the diagnostic value of impedance-pH testing, especially in discriminating patients with GERD from those with functional heartburn. ${ }^{86-88}$ In health, reflux episodes trigger primary peristalsis to neutralise acidified oesophageal mucosa with saliva. This is evident as the antegrade progression of impedance decline within 30s of a reflux episode (PSPW) on a $\mathrm{pH}$-impedance study. ${ }^{87}$ The PSPW index, which currently requires cumbersome manual calculation as it is not programmed into the analysis software, consists of the proportion of reflux episodes on $\mathrm{pH}$-impedance monitoring followed by a PSPW. The PSPW index reflects the integrity of primary peristalsis stimulated by reflux episodes, correlates with contraction reserve assessed using multiple rapid swallows (MRS) ${ }^{89}$ and has excellent performance characteristics in differentiating erosive oesophagitis and pathological acid exposure from functional heartburn and controls (sensitivity $99 \%-100 \%$, specificity $92 \%$ ). ${ }^{8790}$

Baseline impedance values reflect the permeability of the oesophageal mucosa, both in animal models and healthy volunteers, with lower values found in erosive and non-erosive GERD. ${ }^{91}{ }^{92}$ Low baseline oesophageal mucosal impedance has been linked to alteration in intercellular space and tight junctions ${ }^{9394}$ and to reflux symptoms. ${ }^{95}$ Since frequent swallows and reflux events impact measurement, baseline impedance is best measured from $\mathrm{pH}$-impedance tracings during sleep, termed mean nocturnal baseline impedance (MNBI) when averaged from three $10 \mathrm{~min}$ periods spaced an hour apart. ${ }^{84} \mathrm{MNBI}$ is lower in persisting erosive oesophagitis compared with healed 
oesophagitis, ${ }^{96}$ in PPI-responsive NERD and chronic cough compared with PPI-refractory states, ${ }^{84} 97$ and in erosive oesophagitis, NERD and reflux hypersensitivity compared with functional heartburn and healthy controls. ${ }^{868793}$ Low MNBI $(<2292$ ohms) independently predicts response to antireflux therapy, ${ }^{98}$ links PPI responsive heartburn to reflux better than $\mathrm{AET}^{90}$ and improves with healing oesophagitis. ${ }^{99} 100$

Baseline impedance can also be directly measured from the oesophageal mucosa. Initially, this was done using probes with impedance sensors that were passed through the endoscope. Subsequently, the design has improved using two radial sensors mounted on a $10 \mathrm{~cm}$ balloon that is inflated to insure optimal contact with a long segment of oesophageal mucosa. Baseline mucosal impedance values correlate with oesophageal mucosal inflammation, differentiating erosive and non-erosive GERD from eosinophilic oesophagitis and normal patients with better specificity (95\% vs 64\%) and positive predictive value (96\% vs $40 \%$ ) compared with $\mathrm{pH}$ monitoring. ${ }^{101-103}$ Similar to baseline impedance from $\mathrm{pH}$-impedance monitoring, values normalise following PPI therapy. Although normative values are not yet available, ongoing studies should clarify the role of mucosal impedance measurements in GERD management.

\section{Oesophageal high-resolution manometry}

A common indication for high-resolution manometry (HRM) is to accurately place $\mathrm{pH}$ or $\mathrm{pH}$-impedance catheters. HRM is also used to assess peristalsis and to detect alternative major motor disorders prior to ARS or when symptoms do not improve with GERD therapy. Consequently, HRM studies are often performed in the setting of GERD. Nonetheless, although fundamental to GERD pathophysiology, a pathophysiological classification of motor findings in GERD was only recently described.?

\section{EGJ barrier function}

The most fundamental abnormality in GERD is incompetence of the EGJ as an antireflux barrier, making quantifying EGJ competence an attractive biomarker. However, the EGJ is a complex sphincter composed of both the crural diaphragm (CD) and lower oesophageal sphincter (LES), the relative dominance of which varies with circumstance. The EGJ pressure varies with time, respiration and swallowing; similarly the EGJ morphology can also vary over time, transitioning between superimposed and separated CD and LES elements. ${ }^{104}$ Furthermore, some degree of EGJ incompetence is physiological, evident by the phenomenon of transient LES relaxation (TLESR), reflex relaxation of both

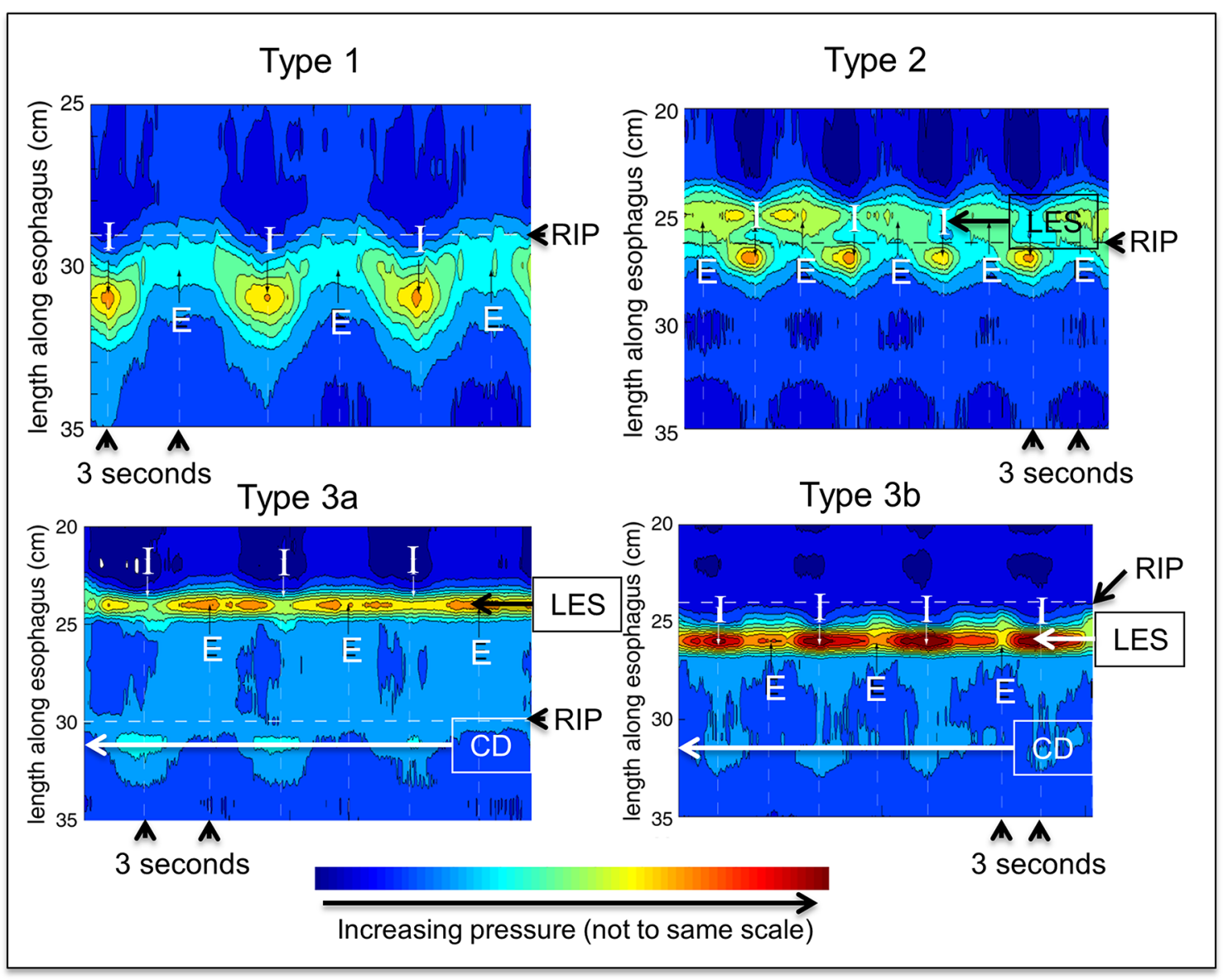

Figure 1 Oesophagogastric junction morphology as depicted in HRM. With type 1 morphology the crural diaphragm (CD) component, evident during inspiration (I), is completely superimposed of the lower oesophageal sphincter (LES) component such that the magnitude of the actual LES pressure is not discernible. With type 2 morphology, there is partial separation of the LES and CD constituents, but the respiratory inversion point (RIP) remains at the level of the CD, evident by the decrease observed in the LES pressure band during inspiration. Other characteristics of type 2 morphology are that the LES-CD separation is $<3 \mathrm{~cm}$ and that the pressure trough between the LES and CD is greater than intragastric pressure. With type 3 morphology, there is $\geq 3 \mathrm{~cm}$ separation between the LES and CD and the pressure trough between the two is equal to intragastric pressure during expiration (E). However, the RIP remains at the level of the CD in type $3 \mathrm{a}$ and elevated to the level of the LES pressure band with type $3 \mathrm{~b}$. This is evident by the decreases in LES pressure during inspiration in type 3a and increases in LES pressure during inspiration in type 3b. 


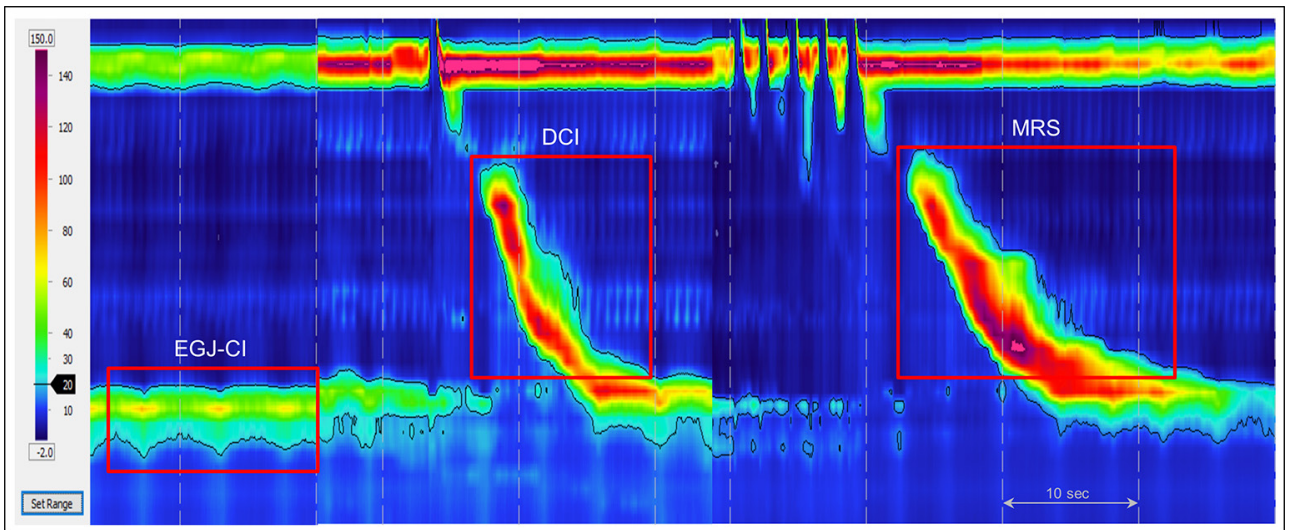

Figure 2 High-resolution manometry metrics used in the motor classification of GERD. The oesophagogastric junction contractile integral (EGJ-CI) measures vigour of the EGJ barrier using a software tool that encompasses length and vigour of the EGJ above the gastric baseline. The measurement is made over three respiratory cycles during quiet rest, and corrected for duration of respiration. The distal contractile integral (DCI) measures vigour of smooth muscle contraction taking length, duration and amplitude of contraction into consideration. Following a series of repetitive swallows (multiple rapid swallows (MRS)), DCl augments higher than mean DCI from single swallows when there is contraction reserve.

the LES and CD that facilitates gas venting from the stomach. ${ }^{105}$ Clearly, there are challenges to quantifying EGJ barrier function.

No single HRM metric adequately summarises EGJ competence. Hence, the Lyon Consensus proposes adopting two metrics, one expressing the anatomical morphology of the EGJ and the second summarising its contractile vigour. EGJ morphology, defined by the relationship between the LES and CD, has been characterised into three subtypes on $\mathrm{HRM}^{106}{ }^{107}$ : type 1 with superimposed LES and CD, type 2 with axially separated LES and CD pressure signals separated by $<3 \mathrm{~cm}$ and type 3 with $a \geq 3 \mathrm{~cm}$ separation between the LES and CD pressure signatures (figure 1). Type 3 EGJ morphology is associated with reduced LES pressure

Table 1 Studies that have compared the EGJ-Cl among patient and control populations. Values reported at median (IQR)

\begin{tabular}{|c|c|c|c|}
\hline Study & Subject groups & $\begin{array}{l}\mathrm{EGJ}-\mathrm{Cl} \\
(\mathrm{mm} \mathrm{Hg} \cdot \mathrm{cm})\end{array}$ & Notes \\
\hline Nicodème et a/ ${ }^{110}$ & $\begin{array}{l}\text { Controls }(n=75) \\
\text { GERD }(n=7) \\
\text { Functional }(n=45)\end{array}$ & $\begin{array}{l}39(25-55) \\
18^{*}(8-30) \\
27(17-69)\end{array}$ & $\begin{array}{l}\text { GERD } \\
\text { had +++ abnormal pH- } \\
\text { impedance studies } \\
\text { vs partial + or - for } \\
\text { functional }\end{array}$ \\
\hline Tolone et $\left.a\right|^{111}$ & $\begin{array}{l}\text { Functional }(n=39) \\
\text { GERD }(n=91)\end{array}$ & $\begin{array}{l}22(10-41) \\
11^{*}(3-21)\end{array}$ & $\begin{array}{l}\text { GERD or functional by } \\
\text { endoscopy and pH- } \\
\text { impedance testing }\end{array}$ \\
\hline Jasper et al ${ }^{112}$ & $\begin{array}{l}\text { Controls }(n=65) \\
\text { GERD }(n=116)\end{array}$ & $\begin{array}{l}63(50-90) \\
50^{*}(28-70)\end{array}$ & GERD by pH-metry \\
\hline Wang et $a^{113}$ & $\begin{array}{l}\text { Controls }(n=21) \\
\text { GERD }(n=68)\end{array}$ & $\begin{array}{l}35(26-58) \\
30 *(15-53)\end{array}$ & $\begin{array}{l}\text { GERD patients } \\
\text { underwent } \\
\text { fundoplication }\end{array}$ \\
\hline Xie et al ${ }^{114}$ & $\begin{array}{l}\text { Controls }(n=21) \\
\text { Oesophagitis }(n=39) \\
\text { NERD }(n=38) \\
\text { Hypersensitive } \\
(n=21)\end{array}$ & $\begin{array}{l}63(38-83) \\
22^{*}(20-31) \\
26^{*}(15-38) \\
30^{*}(19-44)\end{array}$ & $\begin{array}{l}\text { Patients differentiated } \\
\text { by pH-impedance and } \\
\text { symptom correlation }\end{array}$ \\
\hline Ham et al ${ }^{108}$ & $\begin{array}{l}\text { Controls }(n=23) \\
\text { Oesophagitis }(n=25) \\
\text { NERD }(n=16) \\
\text { Non-GERD }((n=91)\end{array}$ & $\begin{array}{l}67(27-79) \\
28^{*}(4-63) \\
26^{*}(15--32) \\
51(3-153)\end{array}$ & $\begin{array}{l}\text { Patients with no GERD } \\
\text { had negative } \mathrm{pH}- \\
\text { impedance studies }\end{array}$ \\
\hline
\end{tabular}

Methods of EGJ-Cl computation were not uniform between these studies, and this might explain differences in calculated thresholds. NERD: non-erosive reflux disease. ${ }^{*} \mathrm{P}<0.05$ vs controls or comparator.

EGJ-Cl, oesophagogastric junction contractile integral; NERD: non-erosive reflux disease. and lower inspiratory augmentation, which correlates with reflux severity. ${ }^{106108109}$ However, this relationship is not linear and there are clear exceptions.

The second HRM metric to quantify EGJ barrier function is the EGJ contractile integral (EGJ-CI) (figure 2). The EGJ-CI is calculated using methodology analogous to that for calculating the distal contractile integral (DCI) with the DCI box set to encompass the LES and CD over a period of three respiratory cycles above a threshold of gastric pressure. The calculated 'DCI' is then divided by the duration of the three respiratory cycles to make it independent of time and expressed in units of $\mathrm{mm} \mathrm{Hg} \cdot \mathrm{cm} .{ }^{110}$ Several groups of investigators have subsequently tested the performance of the EGJ-CI in segregating GERD populations (table 1), ${ }^{110-114}$ with general agreement that this metric identifies a subset of patients with severe barrier dysfunction prone to either endoscopic oesophagitis or unequivocally abnormal reflux testing. However, it is also evident from the spread of normal ranges reported among these studies that there are likely methodological discrepancies in exactly how the EGJ-CI is calculated. In view of this, the Lyon Consensus concluded that the EGJ-CI is a promising metric, but needs further research before widespread adoption. In an attempt to standardise methodology among groups, they recommended exclusion of CD component of the EGJ in instances of type 3 EGJ morphology and calculation of EGJ-CI above the gastric baseline pressure.

Further insight into the genesis of the EGJ-CI has been gleaned through studies using three-dimensional (3D)-HRM. ${ }^{115}$ Isolation of the CD component of the composite EGJ signal on 3D-HRM concluded that approximately $85 \%$ of overall EGJ contractility was attributable to the CD. ${ }^{116}$ Furthermore, analysis of 3D-HRM recordings differentiating the $\mathrm{CD}$ and LES constituents of the EGJ pressure complex demonstrated that the CD component correlated strongly with the EGJ-CI, suggesting that both are largely determined by CD contractility. ${ }^{117}$ Together, these studies provide physiological support for adopting the EGJ-CI as a good summary metric of EGJ barrier function, although with the caveat that the metric is largely an indicator of CD contractility.

\section{Oesophageal peristaltic function}

Oesophageal peristalsis can be characterised by the DCI which summarises the vigour of post-transition zone contraction (figure 2). ${ }^{107}$ A DCI threshold of $450 \mathrm{~mm} \mathrm{Hg} \cdot \mathrm{cm} \cdot \mathrm{s}$ correlates with an averaged distal peristaltic amplitude of $30 \mathrm{~mm} \mathrm{Hg}^{118}$, 
Table 2 Classification of motor function in GERD using oesophageal high-resolution manometry

\begin{tabular}{lll}
\hline & Metrics & Description \\
\hline EGJ barrier function & & \\
\hline Morphology & Separation between LES and CD & $\begin{array}{l}\text { Type 1: superimposed LES and CD } \\
\text { Type 2: axially separated LES and CD pressure signals separated by } \\
<3 \mathrm{~cm}\end{array}$ \\
& & $\begin{array}{l}\text { Type } 3 \mathrm{a}: \geq 3 \mathrm{~cm} \text { separation between the LES and CD pressure } \\
\text { signatures with respiratory inversion point at the level of the CD } \\
\text { Type } 3 \mathrm{~b}: \geq 3 \mathrm{~cm} \text { separation between the LES and CD pressure }\end{array}$ \\
& & signatures with respiratory inversion point at the level of the LES \\
\hline Vigour & DCI box set to encompass the LES and CD over a period of three \\
& & complete respiratory cycles above a threshold pressure of the gastric \\
& &
\end{tabular}

Oesophageal body motor function

Distal contractile integral, $\mathrm{DCl}(\mathrm{mm} \mathrm{Hg} \cdot \mathrm{cm} \cdot \mathrm{s})$ Defect (measure at $20 \mathrm{~mm} \mathrm{Hg}$ isobaric contour)
Intact: $\geq 50 \%$ of contractions with $\mathrm{DCl}>450 \mathrm{~mm} \mathrm{Hg} \cdot \mathrm{cm} \cdot \mathrm{s}$ and no defect Fragmented: $\geq 50 \%$ of contractions with $\mathrm{DCl}>450 \mathrm{~mm} \mathrm{Hg} \cdot \mathrm{cm} \cdot \mathrm{s}$ and defect $>5 \mathrm{~cm}$

Ineffective oesophageal motility: $\geq 50 \%$ of contractions with DCl

$<450 \mathrm{~mm} \mathrm{Hg} \cdot \mathrm{cm} \cdot \mathrm{s}$

Absent peristalsis: $100 \%$ of contractions with $\mathrm{DCl}<100 \mathrm{~mm} \mathrm{Hg} \cdot \mathrm{cm} \cdot \mathrm{s}$

Provocative tests

MRS (five liquid swallows— $2 \mathrm{~mL}$ each—-taken

$<4$ s apart)

RDC (free water drinking of $200 \mathrm{~mL}$ of water within 30s)

$\begin{array}{ll}\text { Contractile response } & \text { Post-MRS DCl augmentation } \\ \text { Failure of contractile response } & \text { Absent post-MRS contraction } \\ \text { Panoesophageal pressurisation } & \\ \text { LES relaxation } & \\ \text { Effective post-RDC contraction } & \end{array}$

Effective post-RDC contraction the original manometric threshold defining ineffective swallows. When abnormal, oesophageal peristalsis is often weak in GERD, ${ }^{119-121}$ with poor and/or delayed formation of post-transition zone contraction segment. ${ }^{122}$ This can result in major breaks $(>5 \mathrm{~cm})$ in the peristaltic contour even when contraction vigour is preserved, a condition termed fragmented peristalsis when $\geq 50 \%$ of test swallows demonstrate this finding. ${ }^{107}$

Peristaltic dysfunction becomes progressively more common going from NERD to erosive oesophagitis, to Barrett's oesophagus. ${ }^{123124}$ High proportions of ineffective contractions increase the likelihood of abnormal AET, particularly while supine, ${ }^{125}$ and increase the likelihood of reflux symptoms. ${ }^{126}$ The Chicago Classification defines ineffective oesophageal motility (IEM) as $\geq 50 \%$ of test swallows with DCI $<450 \mathrm{~mm} \mathrm{Hg} \cdot \mathrm{cm} \cdot \mathrm{s}$, inclusive of any combination of weak (DCI $100-450 \mathrm{~mm} \mathrm{Hg} \cdot \mathrm{cm} \cdot \mathrm{s}$ ) or failed (DCI $<100 \mathrm{~mm} \mathrm{Hg} \cdot \mathrm{cm} \cdot \mathrm{s}$ ) sequences. ${ }^{107}$ Failed sequences are more predictive of an abnormal AET than a similar proportion of weak sequences. ${ }^{127}$ The greatest reflux burden is seen with absent contractility (100\% of test swallows with DCI $<100 \mathrm{~mm} \mathrm{Hg} \cdot \mathrm{cm} \cdot \mathrm{s}){ }^{128}$

\section{Provocative tests}

The physiological phenomenon of deglutitive inhibition is more pronounced with multiple swallows in rapid succession such that the oesophagus remains in inhibition until after the final swallow, which is then followed by a peristaltic contraction. ${ }^{129}$ MRS and rapid drink challenge (RDC) are two provocative tests of the integrity of deglutitive inhibition during HRM. ${ }^{130}$ With MRS, five $2 \mathrm{~mL}$ swallows are taken $<4 \mathrm{~s}$ apart and with RDC $200 \mathrm{~mL}$ of water is swallowed within $30 \mathrm{~s}$. The Lyon Consensus proposes that every HRM study should be accompanied by at least one of these provocative tests.

Post-MRS contractions are an indicator of 'contraction reserve' in the oesophagus, the phenomenon wherein the post-MRS contraction has greater DCI than the preceding test swallows (figure 2). ${ }^{131}$ Recent data suggest three MRS sequences for reliable assessment of contraction reserve. ${ }^{132}$ The absence of contraction reserve in IEM is predictive of the poor efficacy of promotility drugs, ${ }^{133}$ higher AET in NERD,${ }^{89}$ outlet obstruction and subsequent benefit from dilation following ARS ${ }^{134} 135$ and persistence or development of IEM after ARS. ${ }^{136}$ Absent contraction reserve is also the most common manometric finding in systemic sclerosis. ${ }^{137}$ The Lyon Consensus accepted the value of adopting MRS into HRM protocols for determining contraction reserve in IEM or absent contractility, ${ }^{107}$ acknowledging that MRS is the most widely studied provocative test, ${ }^{131} 135138$ provides a computationally simple endpoint (peristaltic augmentation ratio: post-MRS vs pre-MRS) ${ }^{137}$ and is quick and easy to perform.

In contrast to MRS, the most important clinical application of RDC is in distinguishing EGJ obstruction from achalasia, by identifying LES relaxation in the former, and an exaggerated pressure gradient across a non-relaxed EGJ in the latter. ${ }^{139-141}$ Therefore, RDC is most helpful in detecting panoesophageal pressurisation in achalasia, identifying increased resistance to EGJ outflow and uncovering latent hypercontractility. ${ }^{139}$ Additionally, RDC may offer supportive evidence for erosive GERD; effective post-RDC peristalsis was seen in $83 \%$ of healthy controls compared with $70 \%$ of patients with NERD and only $30 \%$ of patients with erosive oesophagitis. ${ }^{142}$ Solid test meals have also been used as provocative tests during HRM, mainly in evaluating transit symptoms. ${ }^{142-145}$ Normal values of oesophageal pressure responses to RDC and solid meals have been recently reported in normal healthy volunteers. ${ }^{145} 146$

HRM studies performed during the postprandial period could be of interest for identification of pathophysiological mechanisms in GERD, ${ }^{147} 148$ particularly reflux episodes that tend to be postprandial. A reflux episode may occur during a TLESR, from low LES pressure, or in conjunction with rumination (increased gastric pressure with or without decreased thoracic pressure) or supragastric 
Table 3 Comparison of the Porto and the Lyon Consensus conclusions

\begin{tabular}{|c|c|}
\hline Porto Consensus & Lyon Consensus \\
\hline No discussion of endoscopy & $\begin{array}{l}\text { Conclusive endoscopic criteria for GERD } \\
\text { LA grade C or D oesophagitis; } \\
\text { Biopsy-proven Barrett's oesophagus; } \\
\text { Peptic stricture. }\end{array}$ \\
\hline $\begin{array}{l}\text { Oesophageal impedance monitoring is the only recording method that can } \\
\text { achieve high sensitivity for detection of all types of reflux episodes while pH } \\
\text { monitoring is required for characterisation of reflux acidity. However, the role } \\
\text { of impedance monitoring in the management of patients with GERD still needs } \\
\text { to be defined. }\end{array}$ & $\begin{array}{l}\text { pH-impedance monitoring is the gold standard for detection and characterisation of reflux } \\
\text { episodes but is expensive, not widely available and interpretation is time consuming. } \\
\text { When reflux monitoring is indicated on PPI, pH-impedance should be performed. } \\
\text { When reflux monitoring is indicated off PPI, the choice between catheter-based pH-monitoring, } \\
\text { wireless pH monitoring and pH-impedance monitoring is dependent on cost and availability. }\end{array}$ \\
\hline No discussion of the conditions (off or on PPI) to perform reflux testing & $\begin{array}{l}\text { Reflux monitoring is recommended off PPI in instances of 'unproven' GERD and on PPI in } \\
\text { instances of 'proven GERD' (previous LA grade C or D oesophagitis, biopsy-proven Barrett's } \\
\text { oesophagus, peptic stricture or AET off PPI > } 6 \% \text { ). }\end{array}$ \\
\hline No discussion of normal values & $\begin{array}{l}\text { An AET }<4 \% \text { is normal and an AET }>6 \% \text { is abnormal (whatever the type of reflux monitoring and } \\
\text { whether the study was performed off or on PPI). }\end{array}$ \\
\hline No discussion of normal values & $\begin{array}{l}\text { Reflux episodes }>80 / 24 \text { hours is abnormal and }<40 \text { is physiological on } \mathrm{pH} \text {-impedance performed } \\
\text { off or on PPI. Number of reflux episodes is an adjunctive metric to be used when AET is borderline } \\
\text { or inconclusive. }\end{array}$ \\
\hline $\begin{array}{l}\text { Basal intraluminal impedance is abnormally low in patients with oesophageal } \\
\text { mucosal abnormalities such as Barrett's oesophagus or oesophagitis. }\end{array}$ & $\begin{array}{l}\text { Measurement of baseline mucosal impedance (using either through the scope device or MNBI } \\
\text { during ambulatory pH-impedance monitoring) is an adjunctive metric for the diagnosis of GERD. }\end{array}$ \\
\hline No discussion of reflux-symptom association & $\begin{array}{l}\text { A combination of a positive SI and positive SAP provides the best evidence of clinically relevant } \\
\text { association between reflux episodes and symptoms. }\end{array}$ \\
\hline $\begin{array}{l}\text { Using manometry, common cavities occur during a higher proportion of reflux } \\
\text { episodes in neonates and infants than in adults. } \\
\text { No discussion of oesophageal motor function in GERD }\end{array}$ & $\begin{array}{l}\text { Oesophageal high-resolution manometry is not useful for the direct diagnosis of GERD but can } \\
\text { provide adjunctive information: } \\
\text { to assess EGJ barrier function including its morphology (type I to III) and its vigour (using } \\
\text { EGJ-CI); } \\
\text { to evaluate oesophageal body motor function (intact, ineffective, fragmented or absent } \\
\text { contractility) that correlates with oesophageal reflux burden; } \\
\text { adjunctive tests should be included in the HRM protocol; } \\
\text { to evaluate the contractile response (multiple rapid swallow); } \\
\text { to evaluate EGJ obstruction (rapid drink challenge test). }\end{array}$ \\
\hline $\begin{array}{l}\text { Bilitec is a monitoring system that can detect duodeno-gastro-oesophageal } \\
\text { reflux by using the optical properties of bilirubin. }\end{array}$ & Bilitec is no longer considered a reliable diagnostic tool for GERD and was not discussed. \\
\hline
\end{tabular}

AET, acid exposure time; EGJ-Cl, o sophagogastric junction contractile integral; HRM, high-resolution manometry; PPI, proton pump inhibitors ; SAP, Symptom Association Probability; SI, Symptom Index.

Table 4 GERD phenotypes predicting abnormal reflux burden from clinical evaluation and oesophageal testing

\begin{tabular}{|c|c|c|c|c|}
\hline & \multicolumn{3}{|l|}{ Pathological GERD } & \multirow[b]{2}{*}{ Modifiers } \\
\hline & High likelihood & Intermediate likelihood & Low likelihood & \\
\hline \multicolumn{5}{|l|}{ Clinical phenotypes } \\
\hline Symptoms & Heartburn, acid regurgitation & Chest pain & Cough, laryngeal symptoms & Hypersensitivity and hypervigilance \\
\hline Endoscopy & $\begin{array}{l}\text { High-grade oesophagitis, Barrett's } \\
\text { mucosa, peptic stricture }\end{array}$ & $\begin{array}{l}\text { Low-grade oesophagitis, normal } \\
\text { exam on PPI therapy }\end{array}$ & & Hiatus hernia, ongoing PPI therapy \\
\hline ROME IV & NERD (abnormal pH-metry)* & Symptom response to PPI therapy & $\begin{array}{l}\text { Reflux hypersensitivity functional } \\
\text { heartburn, functional chest pain }\end{array}$ & Hypersensitivity and hypervigilance \\
\hline Lyon Consensus* & Conclusive evidence of GERD & Borderline or inconclusive evidence & Physiological reflux parameters & $\begin{array}{l}\text { Novel metrics } \\
\text { Motor classification }\end{array}$ \\
\hline \multicolumn{5}{|l|}{ Mechanistic phenotypes } \\
\hline Pattern of reflux & $\begin{array}{l}\text { Increased acid exposure } \\
\pm \text { increased numbers of reflux } \\
\text { episodes* }\end{array}$ & $\begin{array}{l}\text { Borderline acid } \\
\text { exposure } \pm \text { borderline numbers of } \\
\text { reflux episodes* }\end{array}$ & Normal reflux metrics & $\begin{array}{l}\text { pH of refluxate, baseline } \\
\text { impedance, hypochlorhydria, } \\
\text { achlorhydria }\end{array}$ \\
\hline Mechanism of reflux & $\begin{array}{l}\text { TLESR } \\
\text { Hypotensive EGJ } \\
\text { Abnormal EGJ morphology }\end{array}$ & $\begin{array}{l}\text { Supragastric belch } \\
\text { Rumination }\end{array}$ & $\begin{array}{l}\text { Normal EGJ morphology and } \\
\text { function }\end{array}$ & Obesity, increased abdominal girth \\
\hline Clearance of refluxate & $\begin{array}{l}\text { Absent contractility } \\
\text { Hiatus hernia }\end{array}$ & $\begin{array}{l}\text { Minor motor disorder } \pm \text { contraction } \\
\text { reserve }\end{array}$ & Normal peristalsis & $\begin{array}{l}\text { Xerostomia, baseline impedance, } \\
\text { PSPW index, motor classification }\end{array}$ \\
\hline $\begin{array}{l}\text { Cognition, perception of } \\
\text { sensation }\end{array}$ & $\begin{array}{l}\text { Appropriate symptom perception, } \\
\text { symptom reflux association }\end{array}$ & Increased perception & $\begin{array}{l}\text { Visceral hypersensitivity, } \\
\text { hypervigilance }\end{array}$ & $\begin{array}{l}\text { Anxiety, depression } \\
\text { Panic disorder }\end{array}$ \\
\hline
\end{tabular}

*As described by the Lyon Consensus, figure 3.

EGD, oesophagogastroduodenoscopy; EGJ, oesophagogastric junction; NERD, non-erosive reflux disease; PSPW, postreflux swallow-induced peristaltic wave; TLESR, transient lower oesophageal sphincter relaxation. 


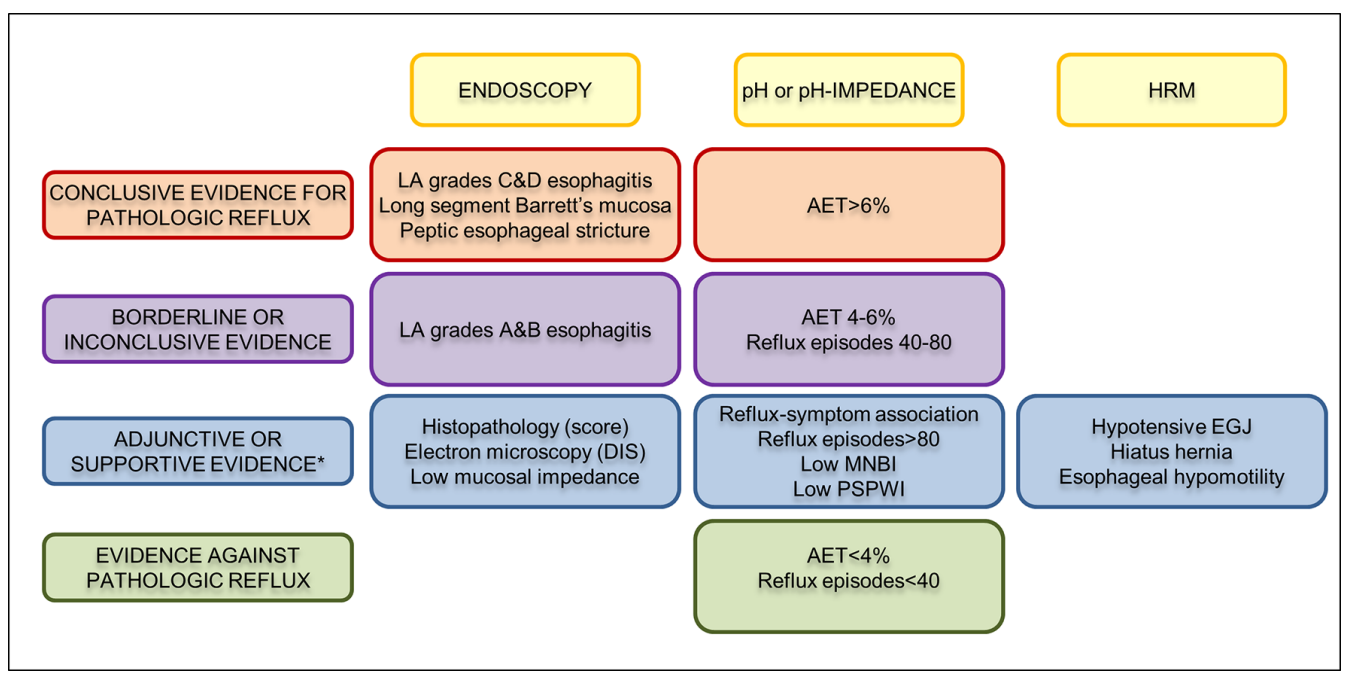

Figure 3 Interpretation of oesophageal test results in the context of GERD. Any one conclusive finding provides strong evidence for the presence of GERD. While a normal EGD does not exclude GERD on its own, this provides strong evidence against GERD when combined with AET $<4 \%$ and $<40$ reflux episodes on $\mathrm{pH}$-impedance monitoring off proton pump inhibitor therapy. When evidence is inconclusive or borderline, adjunctive or supportive findings can add confidence to the presence or absence of GERD. Histopathology as an adjunctive measure requires a dedicated scoring system (incorporating papillary elongation, basal cell hyperplasia, DIS, intraepithelial inflammatory cells, necrosis and erosions) or evidence of DIS on electron microscopy. However, adjunctive findings, particularly histopathology and motor findings in isolation, are not enough to diagnose GERD. AET, acid exposure time; DIS, dilated intercellular spaces; MNBI, mean nocturnal baseline impedance; HRM, high-resolution manometry; PSPWI index, postreflux swallow-induced peristaltic wave index; EGJ, oesophagogastric junction. *Factors that increase confidence for presence of pathological reflux when evidence is otherwise borderline or inconclusive.

belching (air swallowing to initiate belching). ${ }^{147}$ Postprandial HRM has also been used to evaluate the efficacy of drugs targeted to TLESRs, rumination and supragastric belching. ${ }^{149} 150$ However, several limitations exist, including lack of normative postprandial HRM data, difficulties with standardisation of the test meal and unclear optimal duration of the recording period.

\section{Classification of motility findings in GERD}

The most common motility pattern in GERD is a normal study. However, either the EGJ or the oesophageal body, or both can be abnormal. The EGJ can be hypotensive, with or without a hiatus hernia. Peristalsis can be fragmented, ineffective or absent, with or without contraction reserve. The Lyon Consensus endorses the hierarchical classification of motility findings in GERD first evaluating EGJ morphology and function with LES-CD separation and the EGJ-CI, second characterising the integrity of peristalsis as normal, weak, fragmented or absent and third, evaluating for contraction reserve ${ }^{7}$ (table 2). This classification is intended to be used in conjunction with the Chicago Classification.

\section{ADVANCES SINCE THE PORTO CONSENSUS}

The Lyon Consensus builds on the Porto Consensus of 2002, ${ }^{45}$ providing recommendations for the use and interpretation of reflux testing techniques in 2018 including oesophageal HRM and baseline impedance measurement that were not widely available in 2002 (table 3). The primary indication for reflux testing is in distinguishing among patients with pathological reflux burden, reflux-mediated hypersensitivity and functional syndromes (table 4). ${ }^{151}$ The Lyon Consensus attempts to augment this approach by stratifying the significance of findings into those that are conclusive of pathological GERD, as opposed to suggestive of the diagnosis (figure 3). The Lyon Consensus also proposes the concept of 'borderline' or inconclusive evidence when additional evidence can sway the final judgement towards or away from GERD. This is an area where novel metrics and diagnostic techniques may prove helpful. Conditions that can mimic GERD, such as achalasia, supragastric belching and rumination syndrome need to be excluded with appropriate testing.

\section{Optimisation of GERD testing}

GERD symptoms are diverse, response to treatment is variable, pathogenesis is heterogeneous and mechanistic phenotypes are heavily influenced by hypersensitivity and hypervigilance. Because simple algorithms starting with a PPI trial do not consider these complex phenotypes of GERD, they often lead to inappropriate PPI utilisation, delayed diagnosis and inaccurate diagnoses. ${ }^{152}$ The Lyon Consensus opines that the optimal initial testing for PPI non-responders with no prior endoscopic or $\mathrm{pH}$-metry demonstration of GERD is $\mathrm{pH}$ or $\mathrm{pH}$-impedance monitoring done withholding antisecretory therapy. A key potential outcome of that testing is to rule out GERD and to redirect management towards weaning off PPIs, using neuromodulators and/or cognitive behavioural therapy as appropriate. In contrast, optimal testing in poorly responsive patients with a prior demonstration of GERD is the combination of EGD, HRM and $\mathrm{pH}$-impedance monitoring done on twice-daily PPI therapy. This combination of tests serves both to redirect therapy towards alternative diagnoses and to mechanistically subtype patients in terms of poor clearance, excessive reflux episodes and hypersensitivity (table 4), each of which can trigger specific management options. The precise roles of baseline impedance, PSPW index and provocative manoeuvres on HRM remain to be clarified with future research.

\section{Outcome measures in GERD}

The optimal use of diagnostic testing may translate into better therapeutic outcomes, but appropriate outcome measures are necessary to properly evaluate that improvement. Oesophagitis healing is a common measure for therapeutic trials, but visible oesophagitis is rare in patients with refractory GERD symptoms, ${ }^{24}$ and the objective of the evaluation is to determine if refractory symptoms are attributable to GERD or not. Hence, potentially relevant 
outcome measures are symptom description, ${ }^{153}$ symptom questionnaires, ${ }^{154}$ pictograms with visual depictions of symptoms ${ }^{155} 156$ and ambulatory reflux monitoring with analysis of reflux-symptom association. ${ }^{74157}$ Outcome measures typically used in GERD therapeutic trials have included individual symptom assessment with Likert or visual analogue scales, ${ }^{158}$ global outcome evaluations on Likert scales, ${ }^{159}$ adequate versus inadequate relief, disease-specific questionnaires ${ }^{160}$ and quality of life questionnaires. Looking to the future, regulatory agencies have stipulated that validated patient-reported outcome questionnaires (PROs) and quality of life questionnaires will be requisite in future therapeutic trials. Such PROs require a fastidious approach that includes item generation, testing for reliability, responsiveness, validity and interpretability and finally, cross-cultural adaptation when applicable, for each diagnostic category. ${ }^{161}$

\section{CONCLUSIONS AND FUTURE DIRECTION}

GERD is a complex disease with a heterogeneous symptom profile and a multifaceted pathogenic basis that defies a simple diagnostic algorithm or categorical classification. The Lyon Consensus defines parameters on oesophageal testing that conclusively establish the presence of GERD and characteristics that rule out GERD. Additional evidence from reflux-symptom association, motor findings on HRM, novel metrics from $\mathrm{pH}$-impedance monitoring, baseline mucosal impedance and PPI response complement oesophageal testing when $\mathrm{pH}$-metry is borderline or inconclusive. While acknowledging the limitations of currently available oesophageal testing in GERD, the Lyon Consensus proposes this model as a guide to direct management.

The future approach to phenotyping patients with GERD should focus on assessing important physiological biomarkers and PROs to categorise patients based on the severity of refluxate exposure, mechanism of reflux, effectors of clearance and underlying EGJ pathophysiology (table 4), while recognising that no single approach is perfect. Novel metrics assessing tissue resistance, oesophageal clearance, peripheral and central neural integration and psychometrics will allow for a tailored therapeutic approach including pharmacological treatments, surgical/ endoscopic interventions and behavioural strategies targeting the underlying defect(s) in the antireflux barrier, oesophageal clearance, visceral sensitivity and cognitive response to reflux. As newer metrics emerge, the Lyon Consensus plans future meetings to update and adapt the consensus conclusions. Collaboration between high volume medical centres involved in GERD testing has opened possibilities for more robust normative data and for validation of conclusions and recommendations from the Lyon Consensus. As the GERD diagnostic paradigm evolves, using diagnostic testing to define a precision approach tailored to the individual patient becomes possible. The goals of evaluation should therefore transition towards defining GERD phenotypes to facilitate tailored treatment.

\footnotetext{
Author affiliations

'Division of Gastroenterology, Washington University School of Medicine, St Louis, Missouri, USA

2Division of Gastroenterology, Department of Medicine, Northwestern University, Chicago, Illinois, USA

${ }^{3}$ Division of Gastroenterology, Department of Surgical, Oncological and Gastroenterological Sciences, University of Padua, Padua, Italy

${ }^{4}$ Department of Gastroenterology, Bordeaux University Hospital, Université de Bordeaux, Bordeaux, France

${ }^{5}$ Digestive Physiology, Hopital E Herriot, Hospices Civils de Lyon, Université de Lyon, Lyon, France

${ }^{6}$ Digestive Physiology, Université de Lyon, Lyon I University, Lyon, France 'Université de Lyon, Inserm U1032, Lyon, France
}

${ }^{8}$ Department of Gastroenterology and Hepatology, Academic Medical Center, Amsterdam, The Netherlands

${ }^{9}$ Division of Gastroenterology, Vanderbilt University Medical Center, Nashville, Tennessee, USA

${ }^{10}$ Barts and The London School of Medicine and Dentistry, Queen Mary University of London, London, UK

${ }^{11}$ Gastroenterology, St. Claraspital, Kleinriehenstrasse 30, Basel, Switzerland

${ }^{12}$ Zürich Neurogastroenterology and Motility Research Group, Clinic for

Gastroenterology and Hepatology, University Hospital of Zürich, Zürich, Switzerland

${ }^{13}$ Division of Gastroenterology and Hepatology, Mayo Clinic, Scottsdale, Arizona, USA

${ }^{14}$ Division of Gastroenterology, University Clinics for Visceral Surgery and Medicine, Bern University Hospital, Bern, Switzerland

${ }^{15}$ Department of Gastroenterology, Catholic University of Leuven, Leuven, Belgium

Correction notice This article has been corrected since it published Online First. The acknowledgement and funding statements and affiliation for Mark Fox have been updated.

Acknowledgements The authors wish to acknowledge the International Working Group for Gastrointestinal Motility and Function for initiating the consensus meetings and for providing material support for the consensus process. This process was endorsed by the European Society of Neurogastroenterology and Motility (ESNM) with representation and support from members of the American Neurogastroenterology and Motility Society (ANMS), the South American and Latin Society (SLNG), the Asian Neurogastroenterology and Motility Association (ANMA) and members of the Australasian Neurogastroenterology and Motility Association (ANGMA). Financial support was provided by the United European Gastroenterology (UEG) Education Committee, registration fees for meetings and sponsorship from major manufacturers of physiological measurement equipment.

Contributors All authors contributed to the content of the manuscript, and reviewed, edited and approved the final draft.

Funding The consensus process was supported by the Working Group for Gastrointestinal Motility and Function. This group received an educational grant from United European Gastroenterology (UEG).

Competing interests CPG: consulting: Ironwood, Torax, Quintiles; teaching and speaking: Medtronic, Diversatek, Reckitt-Benckiser. ES: consulting: AbbVie, Allergan, MSD, Takeda, Sofar, Janssen; teaching and speaking: Medtronic, Reckitt-Benckiser, Malesci, Zambon. FZ: research support: Medtronic, Sandhill Scientific; consulting: Allergan, Reckitt-Benckiser; speaking and teaching: Ipsen Pharma, Biocodex Coloplast, Takeda, Vifor Pharma, Mayoly Spindler. PJK: consulting: Ironwood. FM: teaching and speaking: Laborie, Medtronic; consulting: Allergan, Endostim. AJPMS: none. MV: Vanderbilt University and Diversatek co-own patent on mucosal impedance technology. DS: research support: Diversatek, Reckitt-Benckiser; OMOM, Jinshan Science \& Technology (Group) Co. Ltd., Chongqing, China. MRF: research support: Given Imaging/Covidien, Reckitt Benckiser, Mui Scientific. Educational events: Given Imaging/Covidien, MMS, Sandhill Scientific Instruments. Speaking and teaching: Given Imaging/Covidien, Reckitt Benckiser, Shire, Almirall. MV: consulting: Torax. RT: teaching: Laborie. JT: consulting: Ironwood. AJB: research support: Danone, Bayer; speaking and/or consulting: MMS, Astellas, AstraZeneca, Bayer, Almirall and Allergan. JP: research support: Impleo; speaking and/or consulting: Medtronic, Diversatek, Torax, Ironwood, Takeda, AstraZeneca; stock options: Crospon. SR: research support: Sandhill Scientific, Crospon; teaching: Medtronic; speaker: Mayoly Spindler.

\section{Provenance and peer review Commissioned; externally peer reviewed.}

Open Access This is an Open Access article distributed in accordance with the Creative Commons Attribution Non Commercial (CC BY-NC 4.0) license, which permits others to distribute, remix, adapt, build upon this work non-commercially, and license their derivative works on different terms, provided the original work is properly cited and the use is non-commercial. See: http://creativecommons.org/ licenses/by-nc/4.0/

(c) Article author(s) (or their employer(s) unless otherwise stated in the text of the article) 2018. All rights reserved. No commercial use is permitted unless otherwise expressly granted.

\section{REFERENCES}

1 El-Serag HB, Sweet S, Winchester CC, et al. Update on the epidemiology of gastrooesophageal reflux disease: a systematic review. Gut 2014;63:871-80.

2 Shaheen NJ, Hansen RA, Morgan DR, et al. The burden of gastrointestinal and liver diseases, 2006. Am J Gastroenterol 2006;101:2128-38.

3 Vakil N, van Zanten SV, Kahrilas P, et al. The Montreal definition and classification of gastroesophageal reflux disease: a global evidence-based consensus. Am J Gastroenterol 2006;101:1900-20. quiz 1943.

4 Katz PO, Gerson LB, Vela MF. Guidelines for the diagnosis and management of gastroesophageal reflux disease. Am J Gastroenterol 2013;108:308-28. quiz 329. 
5 Kahrilas PJ, Boeckxstaens G, Smout AJ. Management of the patient with incomplete response to PPI therapy. Best Pract Res Clin Gastroenterol 2013;27:401-14.

6 Roman S, Gyawali CP, Savarino E, et al. Ambulatory reflux monitoring for diagnosis of gastro-esophageal reflux disease: update of the Porto consensus and recommendations from an international consensus group. Neurogastroenterol Motil 2017:29:1-15.

7 Gyawali CP, Roman S, Bredenoord AJ, et al. Classification of esophageal motor findings in gastro-esophageal reflux disease: conclusions from an international consensus group. Neurogastroenterol Motil 2017;29:e13104.

8 Savarino E, Bredenoord AJ, Fox M, et al. Expert consensus document: Advances in the physiological assessment and diagnosis of GERD. Nat Rev Gastroenterol Hepatol 2017; 14:665-76.

9 Demeester TR, Johnson LF, Joseph GJ, et al. Patterns of gastroesophageal reflux in health and disease. Ann Surg 1976;184:459-70.

10 Lundell LR, Dent J, Bennett JR, et al. Endoscopic assessment of oesophagitis: clinical and functional correlates and further validation of the Los Angeles classification. Gut 1999:45:172-80.

11 Mainie I, Tutuian R, Shay S, et al. Acid and non-acid reflux in patients with persistent symptoms despite acid suppressive therapy: a multicentre study using combined ambulatory impedance-pH monitoring. Gut 2006;55:1398-402.

12 Dent J, Vakil N, Jones R, et al. Accuracy of the diagnosis of GORD by questionnaire, physicians and a trial of proton pump inhibitor treatment: the Diamond Study. Gut 2010;59:714-21.

13 Jones R, Junghard O, Dent J, et al. Development of the GerdQ, a tool for the diagnosis and management of gastro-oesophageal reflux disease in primary care. Aliment Pharmacol Ther 2009:30:1030-8.

14 Bolier EA, Kessing BF, Smout AJ, et al. Systematic review: questionnaires for assessment of gastroesophageal reflux disease. Dis Esophagus 2015:28:105-20.

15 Bytzer P, Jones R, Vakil N, et al. Limited ability of the proton-pump inhibitor test to identify patients with gastroesophageal reflux disease. Clin Gastroenterol Hepatol 2012;10:1360-6.

16 Sifrim D, Zerbib F. Diagnosis and management of patients with reflux symptoms refractory to proton pump inhibitors. Gut 2012;61:1340-54.

17 Gyawali CP, Fass R. Management of Gastroesophageal Reflux Disease. Gastroenterology 2018;154:302-18.

18 Roman S, Keefer L, Imam H, et al. Majority of symptoms in esophageal reflux PPI non-responders are not related to reflux. Neurogastroenterol Motil 2015;27:1667-74.

19 Weijenborg PW, Smout AJ, Verseiiden C, et al. Hypersensitivity to acid is associated with impaired esophageal mucosal integrity in patients with gastroesophageal reflux disease with and without esophagitis. Am J Physiol Gastrointest Liver Physiol 2014;307:G323-9.

20 de Leone A, Tonini M, Dominici P, et al. The proton pump inhibitor test for gastroesophageal reflux disease: optimal cut-off value and duration. Dig Liver Dis 2010;42:785-90.

21 Numans ME, Lau J, de Wit NJ, et al. Short-term treatment with proton-pump inhibitors as a test for gastroesophageal reflux disease: a meta-analysis of diagnostic test characteristics. Ann Intern Med 2004;140:518-27.

22 Jonasson C, Moum B, Bang C, et al. Randomised clinical trial: a comparison between a GerdQ-based algorithm and an endoscopy-based approach for the diagnosis and initial treatment of GERD. Aliment Pharmacol Ther 2012;35:1290-300.

23 Savarino E, Zentilin P, Savarino V. NERD: an umbrella term including heterogeneous subpopulations. Nat Rev Gastroenterol Hepatol 2013;10:371-80.

24 Poh CH, Gasiorowska A, Navarro-Rodriguez T, et al. Upper Gl tract findings in patients with heartburn in whom proton pump inhibitor treatment failed versus those not receiving antireflux treatment. Gastrointest Endosc 2010;71:28-34.

25 Akdamar K, Ertan A, Agrawal NM, et al. Upper gastrointestinal endoscopy in normal asymptomatic volunteers. Gastrointest Endosc 1986;32:78-80.

26 Takashima T, Iwakiri R, Sakata Y, et al. Endoscopic reflux esophagitis and Helicobacter pylori infection in young healthy Japanese volunteers. Digestion 2012;86:55-8

27 Zagari RM, Fuccio L, Wallander MA, et al. Gastro-oesophageal reflux symptoms, oesophagitis and Barrett's oesophagus in the general population: the LoianoMonghidoro study. Gut 2008;57:1354-9.

28 Jobe BA, Richter JE, Hoppo T, et al. Preoperative diagnostic workup before antireflux surgery: an evidence and experience-based consensus of the Esophageal Diagnostic Advisory Panel. J Am Coll Surg 2013;217:586-97.

29 Rex DK, Cummings OW, Shaw M, et al. Screening for Barrett's esophagus in colonoscopy patients with and without heartburn. Gastroenterology 2003:125:1670-7.

30 Sharma P. Review article: prevalence of Barrett's oesophagus and metaplasia at the gastro-oesophageal junction. Aliment Pharmacol Ther 2004;20(Suppl 5):48-54. discussion 61-2

31 Johansson J, Håkansson HO, Mellblom L, et al. Prevalence of precancerous and other metaplasia in the distal oesophagus and gastro-oesophageal junction. Scand J Gastroenterol 2005;40:893-902.

32 Aziz Q, Fass R, Gyawali CP, et al. Functional esophageal disorders. Gastroenterology 2016;150:1368-79
33 Savarino E, Zentilin P, Mastracci L, et al. Microscopic esophagitis distinguishes patients with non-erosive reflux disease from those with functional heartburn. J Gastroenterol 2013;48:473-82.

34 Kandulski A, Jechorek D, Caro C, et al. Histomorphological differentiation of non-erosive reflux disease and functional heartburn in patients with PPI-refractory heartburn. Aliment Pharmacol Ther 2013:38:643-51.

35 Calabrese C, Bortolotti M, Fabbri A, et al. Reversibility of GERD ultrastructural alterations and relief of symptoms after omeprazole treatment. Am J Gastroenterol 2005; 100:537-42

36 Vela MF, Craft BM, Sharma N, et al. Refractory heartburn: comparison of intercellular space diameter in documented GERD vs. functional heartburn. Am J Gastroenterol 2011:106:844-50.

37 van Malenstein H, Farré R, Sifrim D. Esophageal dilated intercellular spaces (DIS) and nonerosive reflux disease. Am J Gastroenterol 2008:103:1021-8.

38 Zentilin P, Savarino V, Mastracci L, et al. Reassessment of the diagnostic value of histology in patients with GERD, using multiple biopsy sites and an appropriate control group. Am J Gastroenterol 2005;100:2299-306.

39 Caviglia R, Ribolsi M, Gentile M, et al. Dilated intercellular spaces and acid reflux at the distal and proximal oesophagus in patients with non-erosive gastro-oesophageal reflux disease. Aliment Pharmacol Ther 2007;25:629-36.

40 Sweis R, Fox M, Anggiansah A, et al. Prolonged, wireless pH-studies have a high diagnostic yield in patients with reflux symptoms and negative 24-h catheter-based pH-studies. Neurogastroenterol Motil 2011;23:419-26.

41 Prakash C, Clouse RE. Value of extended recording time with wireless pH monitoring in evaluating gastroesophageal reflux disease. Clin Gastroenterol Hepatol 2005:3:329-34

42 Ayazi S, Lipham JC, Portale G, et al. Bravo catheter-free pH monitoring: normal values, concordance, optimal diagnostic thresholds, and accuracy. Clin Gastroenterol Hepatol 2009:7:60-7.

43 Scarpulla G, Camilleri S, Galante P, et al. The impact of prolonged pH measurements on the diagnosis of gastroesophageal reflux disease: 4 -day wireless $\mathrm{pH}$ studies. Am J Gastroenterol 2007;102:2642-7.

44 Penagini R, Sweis R, Mauro A, et al. Inconsistency in the diagnosis of functional heartburn: usefulness of prolonged wireless ph monitoring in patients with proton pump inhibitor refractory gastroesophageal reflux disease. J Neurogastroenterol Motil 2015:21:265-72.

45 Sifrim D, Castell D, Dent J, et al. Gastro-oesophageal reflux monitoring: review and consensus report on detection and definitions of acid, non-acid, and gas reflux. Gut 2004;53:1024-31.

46 Savarino E, Marabotto E, Zentilin P, et al. The added value of impedance-pH monitoring to Rome III criteria in distinguishing functional heartburn from nonerosive reflux disease. Dig Liver Dis 2011:43:542-7.

47 Zerbib F, Roman S, Ropert A, et al. Esophageal pH-impedance monitoring and symptom analysis in GERD: a study in patients off and on therapy. Am J Gastroenterol 2006;101:1956-63.

48 Charbel S, Khandwala F, Vaezi MF. The role of esophageal pH monitoring in symptomatic patients on PPI therapy. Am J Gastroenterol 2005;100:283-9.

49 Vela MF, Camacho-Lobato L, Srinivasan R, et al. Simultaneous intraesophagea impedance and $\mathrm{pH}$ measurement of acid and nonacid gastroesophageal reflux: effect of omeprazole. Gastroenterology 2001;120:1599-606.

50 Vaezi MF, Schroeder PL, Richter JE. Reproducibility of proximal probe pH parameters in 24-hour ambulatory esophageal pH monitoring. Am J Gastroenterol 1997:92:825-9

51 McCollough M, Jabbar A, Cacchione R, et al. Proximal sensor data from routine dual-sensor esophageal pH monitoring is often inaccurate. Dig Dis Sci 2004;49:1607-11.

52 Williams RB, Ali GN, Wallace KL, et al. Esophagopharyngeal acid regurgitation: dual $\mathrm{pH}$ monitoring criteria for its detection and insights into mechanisms. Gastroenterology 1999:117:1051-61.

53 Zerbib F, Roman S, Bruley Des Varannes S, et al. Normal values of pharyngeal and esophageal 24-hour pH impedance in individuals on and off therapy and interobserver reproducibility. Clin Gastroenterol Hepatol 2013;11:366-72.

54 Ayazi S, Lipham JC, Hagen JA, et al. A new technique for measurement of pharyngeal pH: normal values and discriminating $\mathrm{pH}$ threshold. J Gastrointest Surg 2009;13:1422-9.

55 Hayat JO, Yazaki E, Moore AT, et al. Objective detection of esophagopharyngeal reflux in patients with hoarseness and endoscopic signs of laryngeal inflammation. J Clin Gastroenterol 2014;48:318-27.

56 Ummarino D, Vandermeulen L, Roosens B, et al. Gastroesophageal reflux evaluation in patients affected by chronic cough: Restech versus multichannel intraluminal impedance/pH metry. Laryngoscope 2013;123:980-4.

57 Wilhelm D, Jell A, Feussner H, et al. Pharyngeal pH monitoring in gastrectomy patients - what do we really measure? United European Gastroenterol J 2016:4:541-5.

58 Wiener GJ, Morgan TM, Copper JB, et al. Ambulatory 24-hour esophageal $\mathrm{pH}$ monitoring. Reproducibility and variability of $\mathrm{pH}$ parameters. Dig Dis SC 1988;33:1127-33. 
59 Patel A, Sayuk GS, Gyawali CP. Parameters on esophageal pH-impedance monitoring that predict outcomes of patients with gastroesophageal reflux disease. Clin Gastroenterol Hepatol 2015;13:884-91.

60 Patel A, Sayuk GS, Gyawali CP. Prevalence, characteristics, and treatment outcomes of reflux hypersensitivity detected on $\mathrm{pH}$-impedance monitoring. Neurogastroenterol Motil 2016;28:1382-90.

61 Roman S, Bruley des Varannes S, Pouderoux P, et al. Ambulatory 24-h oesophageal impedance-pH recordings: reliability of automatic analysis for gastro-oesophageal reflux assessment. Neurogastroenterol Motil 2006;18:978-86.

62 Bell R, Lipham J, Louie BE, et al. Randomized controlled trial of Magnetic Sphincter Augmentation (MSA) vs. omeprazole in gerd patients with regurgitation: initial results from the caliber trial. Gastroenterology 2017;152:\$1309.

63 Bredenoord AJ, Weusten BL, Smout AJ. Symptom association analysis in ambulatory gastro-oesophageal reflux monitoring. Gut 2005:54:1810-7.

64 Lam HG, Breumelhof R, Roelofs JM, et al. What is the optimal time window in symptom analysis of 24-hour esophageal pressure and $\mathrm{pH}$ data? Dig Dis Sci 1994;39:402-9.

65 Herregods TVK, Pauwels A, Tack J, et al. Reflux-cough syndrome: assessment of temporal association between reflux episodes and cough bursts. Neurogastroenterol Motil 2017:29:e13129.

66 Wiener GJ, Richter JE, Copper JB, et al. The symptom index: a clinically important parameter of ambulatory 24-hour esophageal pH monitoring. Am J Gastroenterol 1988;83:358-61.

67 Singh S, Richter JE, Bradley LA, et al. The symptom index. Differential usefulness in suspected acid-related complaints of heartburn and chest pain. Dig Dis Sci 1993;38:1402-8.

68 Weusten BL, Roelofs JM, Akkermans LM, et al. The symptom-association probability: an improved method for symptom analysis of 24-hour esophageal $\mathrm{pH}$ data. Gastroenterology 1994;107:1741-5.

69 Ghillebert G, Janssens J, Vantrappen G, et al. Ambulatory 24 hour intraoesophageal $\mathrm{pH}$ and pressure recordings $\mathrm{v}$ provocation tests in the diagnosis of chest pain of oesophageal origin. Gut 1990;31:738-44.

70 Kushnir VM, Sathyamurthy A, Drapekin J, et al. Assessment of concordance of symptom reflux association tests in ambulatory pH monitoring. Aliment Pharmacol Ther 2012;35:1080-7.

71 Kushnir VM, Sayuk GS, Gyawali CP. Abnormal GERD parameters on ambulatory pH monitoring predict therapeutic success in noncardiac chest pain. Am J Gastroenterol 2010;105:1032-8.

72 Patel A, Sayuk GS, Gyawali CP. Acid-based parameters on pH-impedance testing predict symptom improvement with medical management better than impedance parameters. Am J Gastroentero/ 2014;109:836-44.

73 Watson RG, Tham TC, Johnston BT, et al. Double blind cross-over placebo controlled study of omeprazole in the treatment of patients with reflux symptoms and physiological levels of acid reflux--the "sensitive oesophagus". Gut 1997:40:587-90

74 Taghavi SA, Ghasedi M, Saberi-Firoozi M, et al. Symptom association probability and symptom sensitivity index: preferable but still suboptimal predictors of response to high dose omeprazole. Gut 2005;54:1067-71.

75 Aanen MC, Weusten BL, Numans ME, et al. Effect of proton-pump inhibitor treatment on symptoms and quality of life in GERD patients depends on the symptom-reflux association. J Clin Gastroenterol 2008;42:441-7.

76 Rosen R, Amirault J, Heinz N, et al. The sensitivity of acoustic cough recording relative to intraesophageal pressure recording and patient report during reflux testing. Neurogastroenterol Motil 2014;26:1635-41.

77 Xiao Y, Carson D, Boris L, et al. The acoustic cough monitoring and manometric profile of cough and throat clearing. Dis Esophagus 2014;27:5-12.

78 Bredenoord AJ, Weusten BL, Timmer R, et al. Addition of esophageal impedance monitoring to $\mathrm{pH}$ monitoring increases the yield of symptom association analysis in patients off PPI therapy. Am J Gastroenterol 2006;101:453-9.

79 Tenca A, Campagnola P, Bravi I, et al. Impedance pH monitoring: intra-observer and inter-observer agreement and usefulness of a rapid analysis of symptom reflux association. J Neurogastroenterol Motil 2014;20:205-11.

80 Hemmink GJ, Bredenoord AJ, Weusten BL, et al. Esophageal pH-impedance monitoring in patients with therapy-resistant reflux symptoms: 'on' or 'off' proton pump inhibitor? Am J Gastroenterol 2008; 103:2446-53.

81 Aanen MC, Bredenoord AJ, Numans ME, et al. Reproducibility of symptom association analysis in ambulatory reflux monitoring. Am J Gastroenterol 2008;103:2200-8

82 Slaughter JC, Goutte M, Rymer JA, et al. Caution about overinterpretation of symptom indexes in reflux monitoring for refractory gastroesophageal reflux disease. Clin Gastroenterol Hepatol 2011;9:868-74.

83 Barriga-Rivera A, Elena M, Moya MJ, et al. The binomial symptom index: toward an optimal method for the evaluation of symptom association in gastroesophageal reflux. Neurogastroenterol Motil 2013;25:664-9.

84 Martinucci I, de Bortoli N, Savarino E, et al. Esophageal baseline impedance levels in patients with pathophysiological characteristics of functional heartburn. Neurogastroenterol Motil 2014;26:546-55.
85 Frazzoni M, Bertani H, Manta R, et al. Impairment of chemical clearance is relevant to the pathogenesis of refractory reflux oesophagitis. Dig Liver Dis 2014;46:596-602.

86 de Bortoli N, Martinucci I, Savarino E, et al. Association between baseline impedance values and response proton pump inhibitors in patients with heartburn. Clin Gastroenterol Hepatol 2015;13:1082-8.

87 Frazzoni M, Savarino E, de Bortoli N, et al. Analyses of the post-reflux swallowinduced peristaltic wave index and nocturnal baseline impedance parameters increase the diagnostic yield of impedance-pH monitoring of patients with reflux disease. Clin Gastroenterol Hepatol 2016;14:40-6.

88 Frazzoni M, de Bortoli N, Frazzoni L, et al. Impairment of chemical clearance and mucosal integrity distinguishes hypersensitive esophagus from functional heartburn. J Gastroenterol 2017:52:444-51.

89 Martinucci I, Savarino EV, Pandolfino JE, et al. Vigor of peristalsis during multiple rapid swallows is inversely correlated with acid exposure time in patients with NERD. Neurogastroenterol Motil 2016;28:243-50.

90 Frazzoni L, Frazzoni M, de Bortoli N, et al. Postreflux swallow-induced peristaltic wave index and nocturnal baseline impedance can link PPI-responsive heartburn to reflux better than acid exposure time. Neurogastroentero/ Motil 2017;29:e13116.

91 Farré R, Blondeau K, Clement D, et al. Evaluation of oesophageal mucosa integrity by the intraluminal impedance technique. Gut 2011;60:885-92.

92 Kessing BF, Bredenoord AJ, Weijenborg PW, et al. Esophageal acid exposure decreases intraluminal baseline impedance levels. Am J Gastroenterol 2011;106:2093-7.

93 Kandulski A, Weigt J, Caro C, et al. Esophageal intraluminal baseline impedance differentiates gastroesophageal reflux disease from functional heartburn. Clin Gastroenterol Hepatol 2015;13:1075-81.

94 Zhong C, Duan L, Wang K, et al. Esophageal intraluminal baseline impedance is associated with severity of acid reflux and epithelial structural abnormalities in patients with gastroesophageal reflux disease. J Gastroenterol 2013;48:601-10.

95 Woodland P, Al-Zinaty M, Yazaki E, et al. In vivo evaluation of acid-induced changes in oesophageal mucosa integrity and sensitivity in non-erosive reflux disease. Gut 2013:62:1256-61.

96 Frazzoni M, de Bortoli N, Frazzoni L, et al. The added diagnostic value of postreflux swallow-induced peristaltic wave index and nocturnal baseline impedance in refractory reflux disease studied with on-therapy impedance-pH monitoring. Neurogastroenterol Motil 2017;29:e12947.

97 Ribolsi M, Savarino E, De Bortoli N, et al. Reflux pattern and role of impedance-pH variables in predicting PPI response in patients with suspected GERD-related chronic cough. Aliment Pharmacol Ther 2014;40:966-73.

98 Patel A, Wang D, Sainani N, et al. Distal mean nocturnal baseline impedance on $\mathrm{pH}$-impedance monitoring predicts reflux burden and symptomatic outcome in gastro-oesophageal reflux disease. Aliment Pharmacol Ther 2016;44:890-8.

99 van Rhijn BD, Weijenborg PW, Verheij J, et al. Proton pump inhibitors partially restore mucosal integrity in patients with proton pump inhibitor-responsive esophageal eosinophilia but not eosinophilic esophagitis. Clin Gastroenterol Hepato 2014;12:1815-23

100 Rinsma NF, Farré R, Bouvy ND, et al. The effect of endoscopic fundoplication and proton pump inhibitors on baseline impedance and heartburn severity in GERD patients. Neurogastroenterol Motil 2015:27:220-8.

101 Saritas Yuksel E, Higginbotham T, Slaughter JC, et al. Use of direct, endoscopicguided measurements of mucosal impedance in diagnosis of gastroesophageal reflux disease. Clin Gastroenterol Hepatol 2012;10:1110-6.

102 Katzka DA, Ravi K, Geno DM, et al. Endoscopic mucosal impedance measurements correlate with eosinophilia and dilation of intercellular spaces in patients with eosinophilic esophagitis. Clin Gastroenterol Hepatol 2015:13:1242-8

103 Ates F, Yuksel ES, Higginbotham T, et al. Mucosal impedance discriminates GERD from non-GERD conditions. Gastroenterology 2015;148:334-43.

104 Bredenoord AJ, Weusten BL, Timmer R, et al. Intermittent spatial separation of diaphragm and lower esophageal sphincter favors acidic and weakly acidic reflux. Gastroenterology 2006;130:334-40

105 Roman S, Holloway R, Keller J, et al. Validation of criteria for the definition of transient lower esophageal sphincter relaxations using high-resolution manometry. Neurogastroenterol Motil 2017:29:e12920.

106 Pandolfino JE, Kim H, Ghosh SK, et al. High-resolution manometry of the EGJ: an analysis of crural diaphragm function in GERD. Am J Gastroenterol 2007:102:1056-63.

107 Kahrilas PJ, Bredenoord AJ, Fox M, et al. The Chicago Classification of esophageal motility disorders, v3.0. Neurogastroenterol Motil 2015:27:160-74.

$108 \mathrm{Ham} \mathrm{H}$, Cho YK, Lee HH, et al. Esophagogastric junction contractile integral and morphology: Two high-resolution manometry metrics of the anti-reflux barrier. J Gastroenterol Hepatol 2017;32:1443-9.

109 Tolone S, de Cassan C, de Bortoli N, et al. Esophagogastric junction morphology is associated with a positive impedance-pH monitoring in patients with GERD. Neurogastroenterol Motil 2015;27:1175-82.

110 Nicodème F, Pipa-Muniz M, Khanna K, et al. Quantifying esophagogastric junction contractility with a novel HRM topographic metric, the EGJ-Contractile 
Integral: normative values and preliminary evaluation in PPI non-responders. Neurogastroenterol Motil 2014;26:353-60.

111 Tolone S, De Bortoli N, Marabotto E, et al. Esophagogastric junction contractility for clinical assessment in patients with GERD: a real added value? Neurogastroenterol Motil 2015;27:1423-31.

112 Jasper D, Freitas-Queiroz N, Hollenstein M, et al. Prolonged measurement improves the assessment of the barrier function of the esophago-gastric junction by highresolution manometry. Neurogastroenterol Motil 2017;29:e12925.

113 Wang D, Patel A, Mello M, et al. Esophagogastric junction contractile integral (EGJ-CI) quantifies changes in EGJ barrier function with surgical intervention. Neurogastroenterol Motil 2016;28:639-46.

114 Xie C, Wang J, Li Y, et al. Esophagogastric junction contractility integral reflected the anti-reflux barrier dysfunction in GERD patients. J Neurogastroenterol Motil 2017;23:27-33.

115 Kwiatek MA, Pandolfino JE, Kahrilas PJ. 3D-high resolution manometry of the esophagogastric junction. Neurogastroenterol Motil 2011;23:e461-9.

116 Nicodème F, Soper NJ, Lin Z, et al. Calculation of esophagogastric junction vector volume using three-dimensional high-resolution manometry. Dis Esophagus 2015:28:684-90.

117 Lin Z, Xiao Y, Li Y, et al. Novel 3D high-resolution manometry metrics for quantifying esophagogastric junction contractility. Neurogastroenterol Motil 2017;29:e13054.

118 Xiao Y, Kahrilas PJ, Kwasny MJ, et al. High-resolution manometry correlates of ineffective esophageal motility. Am J Gastroenterol 2012;107:1647-54.

119 Ho SC, Chang CS, Wu CY, et al. Ineffective esophageal motility is a primary motility disorder in gastroesophageal reflux disease. Dig Dis Sci 2002;47:652-6.

120 Diener U, Patti MG, Molena D, et al. Esophageal dysmotility and gastroesophagea reflux disease. J Gastrointest Surg 2001;5:260-5.

121 Chan WW, Haroian LR, Gyawali CP. Value of preoperative esophageal function studies before laparoscopic antireflux surgery. Surg Endosc 2011;25:2943-9.

122 Kumar N, Porter RF, Chanin JM, et al. Analysis of intersegmental trough and proximal latency of smooth muscle contraction using high-resolution esophageal manometry. J Clin Gastroenterol 2012:46:375-81.

123 Meneghetti AT, Tedesco P, Damani T, et al. Esophageal mucosal damage may promote dysmotility and worsen esophageal acid exposure. J Gastrointest Surg 2005:9:1313-7.

124 Savarino E, Gemignani L, Pohl D, et al. Oesophageal motility and bolus transit abnormalities increase in parallel with the severity of gastro-oesophageal reflux disease. Aliment Pharmacol Ther 2011;34:476-86.

125 Fornari F, Blondeau K, Durand L, et al. Relevance of mild ineffective oesophageal motility (IOM) and potential pharmacological reversibility of severe IOM in patients with gastro-oesophageal reflux disease. Aliment Pharmacol Ther 2007;26:1345-54.

126 Blonski W, Vela M, Safder A, et al. Revised criterion for diagnosis of ineffective esophageal motility is associated with more frequent dysphagia and greater bolus transit abnormalities. Am J Gastroenterol 2008;103:699-704.

127 Rengarajan A, Bolkhir A, Gor P, et al. Esophagogastric junction and esophageal body contraction metrics on high-resolution manometry predict esophageal acid burden. Neurogastroenterol Motil 2018;30:e13267

128 Reddy CA, Patel A, Gyawali CP. Impact of symptom burden and health-related quality of life (HRQOL) on esophageal motor diagnoses. Neurogastroenterol Motil 2017:29:e12970.

129 Sifrim D, Jafari J. Deglutitive inhibition, latency between swallow and esophageal contractions and primary esophageal motor disorders. J Neurogastroenterol Motil 2012:18:6-12.

130 Savarino $E$, de Bortoli N, Bellini $M$, et al. Practice guidelines on the use of esophageal manometry - A GISMAD-SIGE-AIGO medical position statement. Dig Liver Dis 2016:48:1124-35.

131 Shaker A, Stoikes N, Drapekin J, et al. Multiple rapid swallow responses during esophageal high-resolution manometry reflect esophageal body peristaltic reserve. Am J Gastroentero/ 2013:108:1706-12.

132 Mauro A, Savarino E, De Bortoli N, et al. Optimal number of multiple rapid swallows needed during high-resolution esophageal manometry for accurate prediction of contraction reserve. Neurogastroenterol Motil 2018;30:e13253.

133 Jafari J, Yazaki E, Woodland P, et al. 370 Effect of azithromycin on Esophageal Hypomotility (EH) and Prediction of response by esophageal stimulations tests during high resolution manometry. Gastroenterology 2015;148:S-75.

134 Stoikes N, Drapekin J, Kushnir V, et al. The value of multiple rapid swallows during preoperative esophageal manometry before laparoscopic antireflux surgery. Surg Endosc 2012;26:3401-7.

135 Wang YT, Tai LF, Yazaki E, et al. Investigation of dysphagia after antireflux surgery by high-resolution manometry: impact of multiple water swallows and a solid test meal on diagnosis, management, and clinical outcome. Clin Gastroenterol Hepatol 2015;13:1575-83.

136 Mello MD, Shriver AR, Li Y, et al. Ineffective esophageal motility phenotypes following fundoplication in gastroesophageal reflux disease. Neurogastroenterol Motil 2016:28:292-8.
137 Carlson DA, Crowell MD, Kimmel JN, et al. Loss of Peristaltic reserve, determined by multiple rapid swallows, is the most frequent esophageal motility abnormality in patients with systemic sclerosis. Clin Gastroenterol Hepatol 2016;14:1502-6.

138 Price LH, Li Y, Patel A, et al. Reproducibility patterns of multiple rapid swallows during high resolution esophageal manometry provide insights into esophageal pathophysiology. Neurogastroenterol Motil 2014;26:646-53.

139 Marin I, Serra J. Patterns of esophageal pressure responses to a rapid drink challenge test in patients with esophageal motility disorders. Neurogastroenterol Motil 2016:28:543-53.

140 Ang D, Hollenstein M, Misselwitz B, et al. Rapid Drink Challenge in high-resolution manometry: an adjunctive test for detection of esophageal motility disorders. Neurogastroenterol Motil 2017;29:e12902.

141 Elvevi A, Mauro A, Pugliese D, et al. Usefulness of low- and high-volume multiple rapid swallowing during high-resolution manometry. Dig Liver Dis 2015:47:103-7.

142 Daum C, Sweis R, Kaufman E, et al. Failure to respond to physiologic challenge characterizes esophageal motility in erosive gastro-esophageal reflux disease. Neurogastroenterol Motil 2011;23:517-e200.

143 Sweis R, Anggiansah A, Wong T, et al. Assessment of esophageal dysfunction and symptoms during and after a standardized test meal: development and clinical validation of a new methodology utilizing high-resolution manometry. Neurogastroenterol Motil 2014;26:215-28.

144 Ang D, Misselwitz B, Hollenstein M, et al. Diagnostic yield of high-resolution manometry with a solid test meal for clinically relevant, symptomatic oesophageal motility disorders: serial diagnostic study. Lancet Gastroenterol Hepatol 2017:2:654-61.

145 Hollenstein M, Thwaites P, Bütikofer S, et al. Pharyngeal swallowing and oesophageal motility during a solid meal test: a prospective study in healthy volunteers and patients with major motility disorders. Lancet Gastroenterol Hepatol 2017:2:644-53.

146 Marin I, Cisternas D, Abrao L, et al. Normal values of esophageal pressure responses to a rapid drink challenge test in healthy subjects: results of a multicenter study. Neurogastroenterol Motil 2017;29:e13021.

147 Yadlapati R, Tye M, Roman S, et al. Postprandial High-Resolution Impedance Manometry Identifies Mechanisms of Nonresponse to Proton Pump Inhibitors. Clin Gastroenterol Hepatol 2018;16:211-8.

148 Ribolsi M, Holloway RH, Emerenziani S, et al. Impedance-high resolution manometry analysis of patients with nonerosive reflux disease. Clin Gastroenterol Hepatol 2014;12:52-7.

149 Boeckxstaens GE, Hirsch DP, Verkleij CB, et al. Reproducibility of meal-induced transient lower oesophageal sphincter relaxations in patients with gastrooesophageal reflux disease. Neurogastroenterol Motil 2005;17:23-8.

150 Kessing BF, Smout AJ, Bredenoord AJ. Clinical applications of esophageal impedance monitoring and high-resolution manometry. Curr Gastroenterol Rep 2012;14:197-205.

151 Galmiche JP, Zerbib F, des Varannes SB. Treatment of GORD: three decades of progress and disappointments. United European Gastroenterol J 2013;1:140-50.

152 Lee WC, Yeh YC, Lacy BE, et al. Timely confirmation of gastro-esophageal reflux disease via $\mathrm{pH}$ monitoring: estimating budget impact on managed care organizations. Curr Med Res Opin 2008;24:1317-27.

153 Hatlebakk JG, Katz PO, Camacho-Lobato L, et al. Proton pump inhibitors: better acid suppression when taken before a meal than without a meal. Aliment Pharmacol Ther 2000:14:1267-72.

154 Carlsson R, Dent J, Watts R, et al. Gastro-oesophageal reflux disease in primary care: an international study of different treatment strategies with omeprazole. International GORD Study Group. Eur J Gastroenterol Hepatol 1998;10:119-24.

155 Tack J, Carbone F, Holvoet L, et al. The use of pictograms improves symptom evaluation by patients with functional dyspepsia. Aliment Pharmacol Ther 2014:40:523-30.

156 Tack J, Caenepeel P, Arts J, et al. Prevalence of acid reflux in functional dyspepsia and its association with symptom profile. Gut 2005;54:1370-6.

157 Desjardin M, Luc G, Collet D, et al. 24-hour pH-impedance monitoring on therapy to select patients with refractory reflux symptoms for antireflux surgery. A single center retrospective study. Neurogastroenterol Motil 2016:28:146-52.

158 Mee AS, Rowley JL. Rapid symptom relief in reflux oesophagitis: a comparison of lansoprazole and omeprazole. Aliment Pharmacol Ther 1996;10:757-63.

159 Richter JE, Kahrilas PJ, Johanson J, et al. Efficacy and safety of esomeprazole compared with omeprazole in GERD patients with erosive esophagitis: a randomized controlled trial. Am J Gastroenterol 2001;96:656-65.

160 Carlsson R, Dent J, Bolling-Sternevald $E$, et al. The usefulness of a structured questionnaire in the assessment of symptomatic gastroesophageal reflux disease. Scand J Gastroenterol 1998;33:1023-9.

161 Alrubaiy L, Hutchings HA, Williams JG. Assessing patient reported outcome measures: a practical guide for gastroenterologists. United European Gastroenterol J $2014: 2: 463-70$ 